\title{
Dielectric characterization of vegetation at $L$ band using an open-ended coaxial probe
}

\author{
Alex Mavrovic $^{1,2}$, Alexandre Roy ${ }^{1,2,3,6}$, Alain Royer ${ }^{1,2}$, Bilal Filali ${ }^{4}$, François Boone $^{5}$, Christoforos Pappas ${ }^{2,6}$, and \\ Oliver Sonnentag 2,6 \\ ${ }^{1}$ Centre d'Applications et de Recherches en Télédétection, Université de Sherbrooke, Sherbrooke, Québec, J1K 2R1, Canada \\ ${ }^{2}$ Centre d'Études Nordiques, Université Laval, Québec, Québec, G1V 0A6, Canada \\ ${ }^{3}$ Département des Sciences de l'Environnement, Université du Québec à Trois-Rivières (UQTR), \\ Trois-Rivières, Québec, G9A 5H7, Canada \\ ${ }^{4}$ Terraprobe Geoscience Corp., Vancouver, British Columbia, V3K 6X7, Canada \\ ${ }^{5}$ Centre de Recherche en Nanofabrication et en Nanocaractérisation, Université de Sherbrooke, \\ Sherbrooke, Québec, J1K 2R1, Canada \\ ${ }^{6}$ Département de géographie, Université de Montréal, Montréal, Québec, H2V 2B8, Canada
}

Correspondence: Alex Mavrovic (alex.mavrovic@usherbrooke.ca)

Received: 12 March 2018 - Discussion started: 28 March 2018

Revised: 19 June 2018 - Accepted: 25 June 2018 - Published: 11 July 2018

\begin{abstract}
Decoupling the integrated microwave signal originating from soil and vegetation remains a challenge for all microwave remote sensing applications. To improve satellite and airborne microwave data products in forest environments, a precise and reliable estimation of the relative permittivity $\left(\varepsilon=\varepsilon^{\prime}-i \varepsilon^{\prime \prime}\right)$ of trees is required. We developed an open-ended coaxial probe suitable for in situ permittivity measurements of tree trunks at L-band frequencies (1$2 \mathrm{GHz}$ ). The probe is characterized by uncertainty ratios under $3.3 \%$ for a broad range of relative permittivities (unitless), [2-40] for $\varepsilon^{\prime}$ and [0.1-20] for $\varepsilon^{\prime \prime}$. We quantified the complex number describing the permittivity of seven different tree species in both frozen and thawed states: black spruce, larch, red spruce, balsam fir, red pine, aspen and black cherry. Permittivity variability is substantial and can range up to $300 \%$ for certain species. Our results show that the permittivity of wood is linked to the freeze-thaw state of vegetation and that even short winter thaw events can lead to an increase in vegetation permittivity. The open-ended coaxial probe proved to be precise enough to capture the diurnal cycle of water storage inside the trunk for the length of the growing season.
\end{abstract}

\section{Introduction}

The current generation of L-band satellite-based radiometers launched over the last decade - the NASA Soil Moisture Active Passive mission (SMAP; Entekhabi et al., 2010), the European Space Agency Soil Moisture Ocean Salinity mission (SMOS; Kerr et al., 2010) and the NASA/CONAE (Comisión Nacional de Actividades Espaciales) joint Aquarius mission (Le Vine et al., 2010) - offer global coverage of L-band (1-2 GHz) observations with a revisit time of only a few days. Although microwave measurements at L-band wavelengths are mostly used to detect soil moisture, ocean salinity and land surface freeze-thaw, these wavelengths are also sensitive to vegetation water content (VWC) since the microwave vegetation optical depth (VOD) is proportional to the VWC of the aboveground biomass (Konings and Gentine, 2017; Wigneron et al., 2017; Ulaby and Long, 2014; Jackson and Schmugge, 1991). However, decoupling the integrated signal originating from soil and vegetation remains challenging for all microwave remote sensing applications (Kerr et al., 2012; Roy et al., 2012, 2014) because vegetation contributes to microwave brightness temperature measurements and thus scatters and attenuates ground surface emissions (Wang et al., 1980; Wigneron et al., 2007). 
Vegetation canopy radiative transfer modeling at $\mathrm{L}$ band remains a challenge when it comes to quantifying the non-negligible scattering and emission effects of vegetation (Wigneron et al., 2017; Kurum et al., 2012). The relative permittivity $\left(\varepsilon=\varepsilon^{\prime}-i \varepsilon^{\prime \prime}\right.$; hereinafter, permittivity refers to relative permittivity for readability) of a vegetation canopy couples its electromagnetic attributes to its physical properties. Current efforts to refine the representation of vegetation canopies in physical microwave radiative transfer models require the quantification of the permittivity of vegetation (Ferrazzoli et al., 2002; Kurum et al., 2011, 2012; Huang et al., 2017). Since the permittivity of trees is difficult to measure in the field at microwave frequencies, it is generally derived from semi-empirical relationships. However, the reliability of this measurement remains to be quantified (Shmugge et al., 1980; Kerr et al., 2010, 2012). The well-known $\omega-\tau$ model used in SMOS and SMAP soil moisture algorithms (Mo et al., 1982; Ulaby et al., 1983; Wigneron et al., 2004) avoids the use of vegetation permittivity by prescribing a single-scattering albedo $(\omega)$ and $\operatorname{VOD}(\tau)$, although it is likely that those two parameters themselves highly depend on the permittivity and VWC. To this day, field measurements of the latter remain challenging (Matheny et al., 2015).

Recent studies examining the impact of vegetation on Lband microwave passive remote sensing have focused mainly on tropical regions and grasslands (Konings et al., 2017a, b). In this paper, we focus on boreal forests, which encompass $\approx 30 \%$ of all global forested area (Brandt et al., 2013). The study of boreal forests is of particular importance for freezethaw event detection, one of the main objectives of both the SMAP and SMOS missions. Detecting these events is important for a better understanding of land surface-atmosphere interactions, including how the timing of the start of the thawing period influences the net ecosystem exchanges of carbon, water and energy (Kim et al., 2014; Panner Selvam et al., 2016; McDonald et al., 2004; Zhang et al., 2011; Chapin et al., 2005).

Freeze-thaw state detection at $\mathrm{L}$ band is based on the dielectric contrast between water and ice at these frequencies (Fig. 1). At L band, permittivity drops when water freezes. For oblique incidence angles ( $>0^{\circ}$ from nadir), horizontal polarization is more affected than its vertical counterpart during the phase change, which offers the possibility of using a polarization ratio as an effective tool for determining soil freeze-thaw status (Roy et al., 2017; Rautiainen et al., 2016). The use of $\mathrm{L}$ band for freeze-thaw detection has been demonstrated experimentally (Derkson et al., 2017; Roy et al., 2015, 2017; Rautiainen et al., 2012, 2014, 2016). However, the permittivity of vegetation in frozen versus thawed conditions is of particular interest for the detection of soil freeze-thaw events, since soil and vegetation might not freeze or thaw concurrently. In midwinter, for example, with air temperatures below the freezing point, trees minimize their physiological activities. During this dormancy phase, sap flow ceases and VWC drops. Some of the water in the tree freezes,

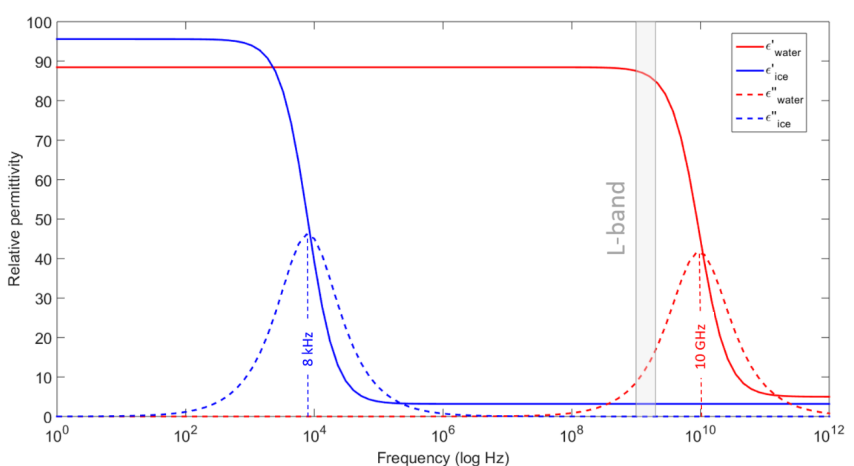

Figure 1. Real $\left(\varepsilon^{\prime}\right)$ and imaginary $\left(\varepsilon^{\prime \prime}\right)$ parts of the relative permittivity (unitless) of water and ice at $273 \mathrm{~K}$ according to the Debye relaxation model (Mätzler, 1987; Artemov and Volkov, 2014).

and the ice fraction in the trunk varies as a function of tree composition and air temperature (Sparks, 2001) and could theoretically lead to a variation in tree permittivity in relation to air temperature.

During the growing season the tree contributions to the L-band signal are related to water fluxes and storage in tree sapwood in accordance with the demonstrated relationship between $\varepsilon$ and VWC (Jackson and Schmugge, 1991). The high liquid water content of sapwood should translate into high wood permittivity in contrast to dry heartwood. Sapwood thickness varies substantially by species and by region (Quiñonez-Piñon and Valeo, 2017).

To our knowledge, only a small number of measurements of tree permittivity at microwave frequencies have been reported (e.g., El-Rayes and Ulaby, 1987; Way et al., 1990; McDonald et al., 2002; Franchois et al., 1998). Most of these studies report limited details on the accuracy and validation of the instruments used to measure permittivity and are restricted in scope. For example, El-Rayes and Ulaby (1987) focused on the measurement of leaf permittivity in a laboratory. The trunks of only two species of tree, balsam fir (Abies balsamea) and black cherry (Prunus serotina), were studied in summer conditions and the temporal variability induced by their diurnal and seasonal biological processes was not considered. It should further be noted that the technique proposed in El-Rayes and Ulaby (1987) is poorly adapted to field conditions and required the tree to be cut down. Even fewer permittivity measurements of vegetation have been attempted in winter conditions (Way et al., 1990). The difference between the summer and winter permittivity of tree trunks could have important impacts on the identification of freeze-thaw cycles in forest environments but this phenomenon remains poorly understood (Roy et al., 2015, 2016).

The goal of this study is to introduce and validate a newly developed open-ended coaxial probe (OECP) for in situ measurements of tree trunk permittivity at L band. The OECP measures a reflection coefficient at the interface between the 
probe and the medium of interest. Subsequently, the permittivity is inferred from its empirical relationship with the reflection coefficient. Section 2 describes the theory behind OECP measurements and their calibration. Section 3 explains the OECP measurement methodology, the study sites and the tree species. In Sects. 4 and 5, the performance, capabilities and limitations of the probe are presented and discussed. Furthermore, vegetation permittivity results during frozen and thawed periods for various species are presented.

\section{Methods}

\subsection{Open-ended coaxial probe measurement principle}

Permittivity $(\mathrm{F} / \mathrm{m})$ describes the reaction of a medium to an external electric field. The relative permittivity (unitless) is the ratio between the permittivity of a medium and vacuum permittivity. Relative permittivity is described by a complex number $\left(\varepsilon=\varepsilon^{\prime}-i \varepsilon^{\prime \prime}\right)$. The real part of the permittivity $\left(\varepsilon^{\prime}\right)$ describes the effect of the reorientation of the electric dipole inside the medium that drives wave propagation, and the imaginary part $\left(\varepsilon^{\prime \prime}\right)$ describes the absorption (or loss) by the medium. It should be noted that the real and imaginary parts are not independent but linked through the Kramers-Kronig relations (Klingshirn, 2012). A high value of real permittivity characterizes a medium that strongly opposes the application of an external electric field (e.g., $\varepsilon^{\prime}$ water $\approx 90$ ). In contrast, a low real permittivity characterizes a medium that does not strongly oppose the application of an external electric field (e.g., $\varepsilon^{\prime}$ air $\approx 1$ ).

The general principle when dealing with permittivity measurements is to calculate the medium response to an applied electric field. Five main techniques are used for measuring this response in the microwave domain: waveguide (Demontoux et al., 2008), transmitting and receiving antenna (Ghodgaonkar et al., 1990), resonant cavity (Hakki and Coleman, 1960; Bircher et al., 2016), transmission line (Topp et al., 1980) and OECP (Stuchly et al., 1982; Demontoux et al., 2016). The first three techniques are more difficult to adapt for in situ field measurements on trees due to their constraints on the geometry of the samples and the size and fragility of the measuring devices (e.g., network analyzer required, sample of a specific shape required to fit in a container).

In this study, we designed, developed and validated an OECP operating at the $\mathrm{L}$ band. The permittivity of the probed medium is inferred from the reflection coefficient $(\rho)$ measured at the interface between the probe and the medium (Fig. 2a). The probe was developed with the requirement that it must be operational during field campaigns in remote forest environments. Therefore, the system had to be easily transportable, reasonably sized in terms of weight and dimensions, low in energy consumption, operational at low temperatures and weatherproof. The design of our probe was inspired by the work of Filali et al. (2006, 2008). Filali et al. (2006) developed an OECP for nondestructive measurements of concrete dielectric properties in the $100-900 \mathrm{MHz}$ spectrum. OECPs are dimension dependent, and thus the radius of the inner conducting cylinder and the dielectric material determine the effective frequency range of the probe. The dimensions of our OECP were chosen to cover the Lband spectrum (centered at $1.4 \mathrm{GHz}$ ). The probe comprises two coaxial conducting cylinders, $65 \mathrm{~mm}$ in length. The inner metal cylinder has a radius of $5 \mathrm{~mm}$, while the outer metal cylinder has inner and outer radii of 16.2 and $30 \mathrm{~mm}$, respectively. The $11.2 \mathrm{~mm}$ gap between the coaxial aluminum cylinders is filled with polytetrafluoroethylene (PTFE), a dielectric material. The probe was custom-made (Atelier Pedro, Sherbrooke, QC, Canada) following Filali et al. (2006, 2008). The OECP generates an electric field through its own coaxial dielectric medium as well as through a medium adjacent to its exposed end (Fig. 2a). The probe's external electric field extends to a distance comparable to the inner diameter of the probe, but its range varies substantially according to the permittivity of the medium studied (Eq. 1). The electric field range defines the thickness of the sampled medium and can be estimated using the penetration depth $\delta_{\mathrm{d}}$ (Eq. 1) describing the travel distance of an electromagnetic plane wave before being attenuated by a factor $1 / e$ where $e$ is the Euler number.

$\delta_{\mathrm{d}}=\frac{c}{2 \pi f} \frac{\sqrt{\varepsilon^{\prime}}}{\varepsilon^{\prime \prime}}$,

where $f$ represents the frequency $(\mathrm{Hz})$, and $c$ is the speed of light in a vacuum $\left(\mathrm{m} \mathrm{s}^{-1}\right)$.

A reflectometer (Planar R54; Copper Mountain Technologies, Indianapolis, IN, USA) was used to measure $\rho$ from the reflected wave at the interface between the probe and the probed medium. We chose to use a low-cost reflectometer such as the Planar R54 (USD 3000) instead of a more expensive network analyzer ( $\sim$ USD 15000) since only the $\rho$ measurement is needed for our OECP. The Planar R54 reflectometer was chosen because of its ease of use in the field, small size and wide operational temperature range (from -40 to $+50^{\circ} \mathrm{C}$ ). The reflectometer connects to a laptop on which manufacturer software is used to control and acquire the $\rho$ data. Figure $2 b$ gives an overview of the complete measurement system.

\subsection{Open-ended coaxial probe calibration}

To obtain the estimate of the medium's permittivity, the OECP must first be calibrated with reference media. The calibration process involves obtaining the calibration parameters necessary to transform $\rho$ into the permittivity of the probed medium. The medium permittivity can be deduced from its admittance $Y$ (inverse of the impedance) obtained by solving 

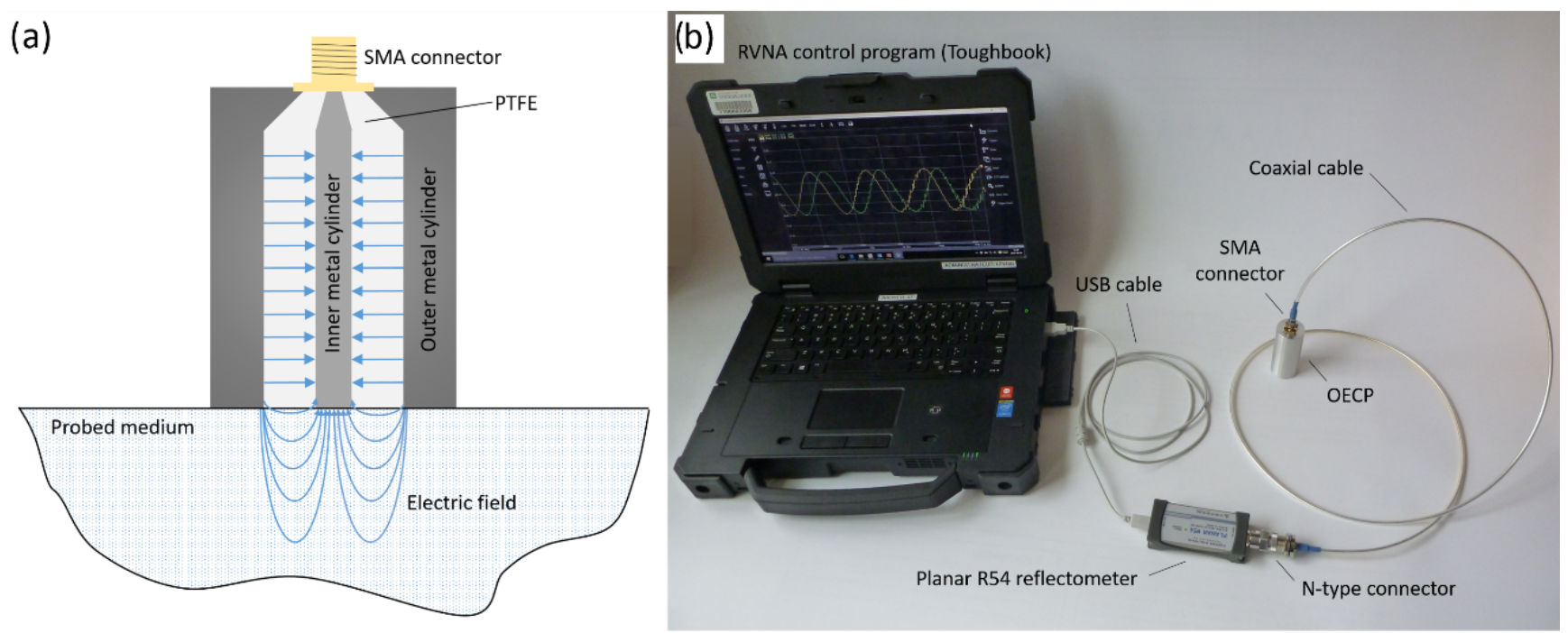

Figure 2. (a) Diagram of the electrical field produced by the open-ended coaxial probe. (b) Open-ended coaxial probe kit for permittivity measurement. The reflectometer manufacturer provides the RVNA control program. An SMA N cable is required to connect the probe to the Planar R54 reflectometer.

the following equation (Filali et al., 2006, 2008):

$Y(\varepsilon)=\frac{2 j k^{2}}{f \mu_{o} \ln \left(\frac{a}{b}\right)} \int_{a}^{b} \int_{a}^{b} \int_{0}^{\pi} \frac{\cos \varphi e^{-j k r}}{r} d \varphi d u d u^{\prime}$,

where $k$ is the wavenumber $\left(k=f \sqrt{\varepsilon_{r} \varepsilon_{o} \mu_{o}}\right)$, $r=\sqrt{\left.u^{2}+u^{\prime 2}+2 u u^{\prime} \cos \varphi\right)}$ in radians per meter, $f$ is the frequency in hertz, $\varepsilon_{r}$ is the media relative permittivity, $\varepsilon_{o}$ is the vacuum absolute permittivity, $\mu_{o}$ is the vacuum absolute permeability, (u, u', $\varphi$ ) are the cylindrical coordinates and $a$ and $b$ represent the internal and external radius of the coaxial probe in meters, respectively. One notices that the integral of Eq. (2) is in cylindrical coordinates. Solving Eq. (2) numerically requires a vast amount of computing power because of integration singularities. Hence, a welldocumented Taylor series approximation is used to make the calculation process much more effective with only subtle differences in results (Blackham and Pollard, 1997). The following equation is derived from the use of the Taylor series approximation of the exponential term in Eq. (2):

$Y(\varepsilon)=\frac{2 j k^{2}}{f \mu_{o} \ln \left(\frac{a}{b}\right)} \sum_{n=0}^{\infty} \frac{k^{n-\frac{1}{2}} I_{n}}{(n-1) !}$,

where

$I_{n}=(-j)^{n-1} \int_{a}^{b} \int_{a}^{b} \int_{0}^{\pi} r^{n-2} \cos \varphi d \varphi d u d u^{\prime}$.

The probe reflection coefficient $\Gamma$ can be obtained using Eq. (5) where $Y_{O}$ represents the admittance of the probe
$\left(Y_{o}=\frac{1}{50} \Omega^{-1}\right)$ and $Y(\varepsilon)$ represents the admittance of the medium.

$\Gamma=\frac{Y(\varepsilon)-Y_{o}}{Y(\varepsilon)+Y_{o}}$

In order to obtain the reflection coefficient $\Gamma$ at the contact interface between the probe and the sample, it is important to know how this coefficient is affected by the components that separate the measuring plane from the reflectometer (reflectometer input connector, coaxial cable and coaxial probe). The following relation connects the reflection coefficient $\rho$ measured by the reflectometer to $\Gamma$ :

$\Gamma=\frac{\rho-S_{11}}{S_{11} \rho+S_{12} S_{21}-S_{11} S_{22}}$,

where $S_{i j}(i, j \in\{1,2\})$ represents the probe scattering parameters. Since Eq. (7) has three unknown parameters $\left(S_{11}\right.$, $S_{12} S_{21}$ and $S_{22}$ ), it is necessary to use at least three reference media with known reflection coefficients $\Gamma$ (or the permittivity) to solve the resulting system of equations (Eq. 7). Here we used an open circuit, a short circuit and a known reference solution as reference media. The reference solutions are saline solutions whose relationship between the $\mathrm{NaCl}$ concentration and the permittivity is described by the Cole-Cole equation (Cole and Cole, 1941) that has previously been verified for this type of application (Nyshadham et al., 1992). A single solution would be sufficient to perform calibration; nevertheless, a set of five saline solutions with concentrations ranging from 10 to 30 parts per thousand (ppt) was used to ensure greater precision. Thus, by measuring $\rho$, it is possible 
to determine $\Gamma$ and then find the probed material permittivity.

$$
\begin{aligned}
& S_{11}=\frac{\Gamma_{1} \Gamma_{2} \rho_{3}\left(\rho_{1}-\rho_{2}\right)+\Gamma_{1} \Gamma_{3} \rho_{2}\left(\rho_{3}-\rho_{1}\right)+\Gamma_{2} \Gamma_{3} \rho_{1}\left(\rho_{2}-\rho_{3}\right)}{\Gamma_{1} \Gamma_{2}\left(\rho_{1}-\rho_{2}\right)+\Gamma_{1} \Gamma_{3}\left(\rho_{3}-\rho_{1}\right)+\Gamma_{2} \Gamma_{3}\left(\rho_{2}-\rho_{3}\right)} \\
& S_{22}=\frac{\Gamma_{1}\left(\rho_{2}-S_{11}\right)+\Gamma_{2}\left(S_{11}-\rho_{1}\right)}{\Gamma_{1} \Gamma_{2}\left(\rho_{2}-\rho_{1}\right)} \\
& S_{12} S_{21}=\frac{\left(\rho_{1}-S_{11}\right)\left(1-S_{22} \Gamma_{1}\right)}{\Gamma_{1}}
\end{aligned}
$$

\subsection{Performance evaluation}

Probed depth is an important parameter needed for permittivity measurements because it indicates the minimum required sample thickness. By measuring the permittivity of a stack of paper sheets with a metallic plate underneath, it is possible to experimentally evaluate the probed depth of the OECP (El-Rayes and Ulaby, 1987). The permittivity of paper is relatively low, around $\varepsilon_{\text {paper }}^{\prime} \approx 2.95$ (El-Rayes and Ulaby, 1987), in contrast to the apparent high permittivity induced by the high reflection coefficient of metallic material at microwave frequencies. Therefore, by increasing the height of the paper stack (i.e., adding more paper sheets) the permittivity stabilizes when the metallic plate no longer affects the probe. The expected penetration depth at $\mathrm{L}$ band for paper is about $9 \mathrm{~mm}$ when calculated using Eq. (1).

To investigate the uncertainty associated with the OECP measurements, liquid and solid standards with well-known permittivities were used to identify any systematic errors and evaluate probe precision. The root mean square error (RMSE) percentage between our measured permittivity and the expected permittivity as found in the scientific literature was calculated to quantify the probe's precision. The four liquid references chosen (ethylene glycol, 1-propanol, 2-propanol and 1-butanol) have well-known frequency and temperature dependencies (Gregory and Clarke, 2012). Furthermore, they do not interact with the probe's materials. For the solid reference, polytetrafluoroethylene (PTFE) was chosen as the permittivity is given by Webster (2003) and it can be easily shaped into an appropriate sample size.

\subsection{Tree permittivity measurements using an open-ended coaxial probe}

One of the main challenges in taking measurements of vegetation material with an OECP is obtaining a smooth surface to ensure full contact between the probe and the solid sample. Any air gap between the probe and the solid wood sample substantially affects the measurement as the low permittivity of air will systematically produce lower permittivity readings. To obtain accurate measurements in tree trunks, a set of Forstner drill bits (Freud Tools Inc., High Point, NC, USA), typically used in woodworking, was modified to create a flat surface at the desired depth in the tree trunk (Fig. 3a). To ensure proper contact, soft rotary tools were used to polish and clean the wood surface (Fig. 3b). Figure 3b shows a typical tangential cut that has been prepared for measurement.
This method for creating a smooth surface in the tree trunk proved to be suitable for obtaining reliable and reproducible permittivity measurements of tree trunks without disturbing the sampling area of the trunk (see Sect. 4.2). Figure 3c demonstrates the process followed to collect the permittivity measurements of the tree. For every depth in a given trunk cavity, two or three measurements were taken. Permittivity results presented in this article are the average of those multiple measurements at the same depth in the examined tree trunks.

During the growing season, due to tree transpiration and associated water flow in the sapwood, OECP measurements must be taken shortly after the cut to avoid an accumulation of sap around the sample area. Repeated measurements after the initial cut show that the measured trunk permittivity remains stable for 2 to $5 \mathrm{~min}$ depending on the species and season (data not shown). Under frozen conditions, this is not a concern since there is no biological reaction in response to the cut. The sapwood depth was estimated visually using tree cores extracted with an increment borer (Maeglin, 1959). Because it was shown that the OECP calibration is temperature dependent, the OECP was always thermalized to the outdoor temperature before calibrations and measurements were taken.

For continuous measurement and to avoid any oozing or drying issues due to the tree's biological reaction to the wound, the gap between the probe and the cavity edges was sealed with plumber's putty. The plumber's putty does not affect measurements because it is placed around the edge of the probe, away from the open-ended measuring surface of the OECP probe. The OECP was inserted into the middle of the sapwood (6 $\mathrm{mm}$ of depth) in a red pine (Pinus resinosa; see Sect. 3.2) for continuous permittivity measurements over several weeks during September 2017. One permittivity measurement was taken every $5 \mathrm{~min}$. Soil moisture EC-TM sensors (Decagon Devices Inc., Pullman, WA, USA) were inserted in the soil at $5 \mathrm{~cm}, 10 \mathrm{~cm}$ and vertical positions around the studied tree to monitor soil water availability.

In this article, the state of the vegetation will be referred to as fully frozen when the soil, air and tree-skin temperatures are permanently below the freezing point. It will be referred to as fully thawed when the soil, air and tree-skin temperatures remain permanently above the freezing point for several consecutive days. A winter thaw event refers to a period when the air and tree-skin temperature rise above the freezing point, while the soil temperature stays below $0{ }^{\circ} \mathrm{C}$.

\section{Study sites}

Tree permittivity measurements were taken at three different sites for a total of seven tree species (five conifers and two hardwoods). For each species, several measurements were obtained at several depths per tree. All measurements were taken at breast height $(\approx 1.3 \mathrm{~m}$ above ground level). The per- 


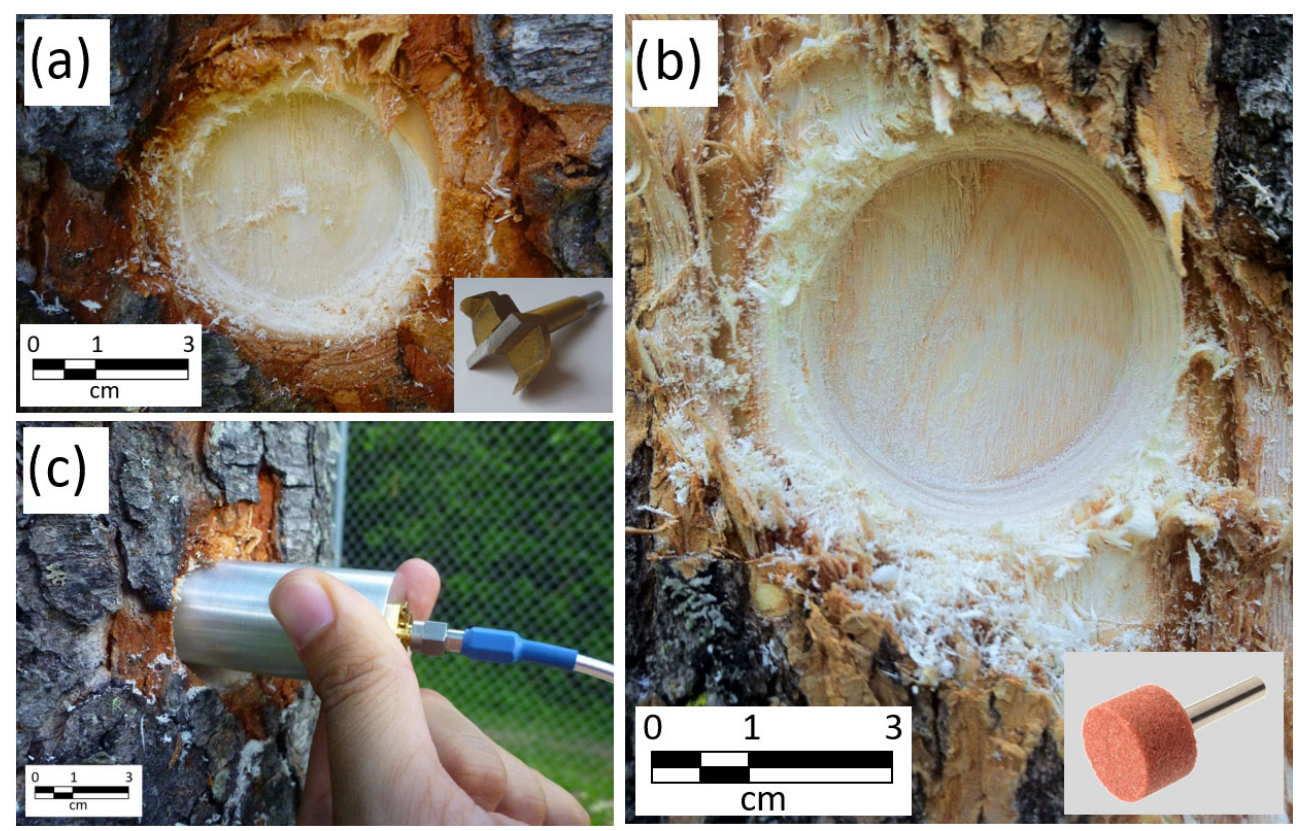

Figure 3. Tangential cut of a black cherry trunk for permittivity measurement. (a) First, a hole is drilled in the trunk using a modified Forstner drill bit. (b) The surface is then flattened using a soft rotary tool. (c) Black cherry trunk permittivity measurement using the OECP. A scale is provided for the images, but not for the tools.

mittivity vertical variability along the trunk was not investigate in this article; a slight increase in permittivity is expected from roots to the top of the tree (Franchois et al., 1998). A detailed description of the sites studied and the measurements obtained can be found in Table 1 .

The Old Black Spruce (OBS) site is located in northern Saskatchewan near Canada's boreal forest southern limit and is composed mainly of black spruce (Picea mariana) with about $10 \%$ larch (Larix laricina) (Gower et al., 1997; Bergeron et al., 2007). For this study, bimonthly measurements of tree permittivity were conducted at the site from January to May 2017. In addition, a 5-day study was conducted starting on 16 September 2016 to capture tree dielectric characteristics towards the end of summer and a second took place starting on 3 May 2017 to capture the spring freeze-thaw transition phase. The Montmorency Forest research site (NEIGEFM) is located in a boreal forest stand in Québec dominated by balsam fir (Abies balsamea) with occasional red spruce (Picea rubens). It was visited four times for 2-day visits starting on 2 November 2016, 18 January 2017, 8 March 2017 and 11 May 2017. The research station Site Interdisciplinaire de Recherche en Environnement Extérieur (SIRENE) is located in a mixed forest stand in Québec dominated by red pine plantation with aspens (Populous tremuloides) and black cherry (Prunus serotina). It was visited seven times between June 2016 and May 2017.

\section{Results}

\subsection{Probed depth}

The permittivity of a stack of paper sheets stabilized at a thickness of $10 \mathrm{~mm}$ (Fig. 4). At that thickness, the effect of paper sheet height is too low to be observed given the probe's precision (see Sect. 4.2). Because the probed depth depends on the permittivity of the material, it is expected that samples with higher permittivity will have a shallower probed depth. The permittivity of paper is close to the lower end of the range of permittivity expected for vegetation material, and thus a $10 \mathrm{~mm}$ measurement should be seen as the upper limit of the probed depth of the OECP. For this reason, all results shown in this article were taken with samples of thickness greater than $10 \mathrm{~mm}$ to ensure there is no measurement disturbance in the probe's effective electrical field.

\subsection{Performance evaluation}

A validation of the OECP performance was conducted by using liquid and solid standards (Fig. 5). The results summarized in Table 2 show consensus between our measurements and the reference data. In the L-band wavelength range, the standard deviation between the reference and measured data is under $2.5 \%$ (Table 2). For some liquids, we can observe the beginning of a deviation out of the frequency domain for which the probe was designed $(1-2 \mathrm{GHz})$. Such deviation was to be expected and can be ignored for our L-band measurements since only the $1-2 \mathrm{GHz}$ range is used. As a 
Table 1. Study sites and tree measurement details for Old Black Spruce (OBS), Montmorency Forest research site (NEIGE-FM) and Site Interdisciplinaire de Recherche en Environnement Extérieur (SIRENE). DBH stands for the diameter of the tree at breast height.

\begin{tabular}{|c|c|c|c|c|c|}
\hline \multirow[t]{2}{*}{ Sites } & \multirow[t]{2}{*}{ GPS coordinates } & \multicolumn{2}{|c|}{ Species } & \multirow{2}{*}{$\begin{array}{r}\text { Number of } \\
\text { measured } \\
\text { trees }\end{array}$} & \multirow{2}{*}{$\begin{array}{r}\text { Average } \mathrm{DBH} \text { in } \\
\mathrm{cm} \text { (standard } \\
\text { deviation) }\end{array}$} \\
\hline & & Common & Latin & & \\
\hline OBS & $\begin{array}{r}53^{\circ} 59^{\prime} 14^{\prime \prime} \mathrm{N} \\
105^{\circ} 07^{\prime} 04^{\prime \prime} \mathrm{W}\end{array}$ & $\begin{array}{l}\text { Black } \\
\text { spruce }\end{array}$ & $\begin{array}{l}\text { Picea } \\
\text { mariana }\end{array}$ & 16 & $11.4(1.6)$ \\
\hline OBS & $\begin{array}{r}53^{\circ} 59^{\prime} 14^{\prime \prime} \mathrm{N} \\
105^{\circ} 07^{\prime} 04^{\prime \prime} \mathrm{W}\end{array}$ & Larch & $\begin{array}{l}\text { Larix } \\
\text { laricina }\end{array}$ & 5 & $22.1(3.5)$ \\
\hline NEIGE-FM & $\begin{array}{l}47^{\circ} 19^{\prime} 20^{\prime \prime} \mathrm{N} \\
71^{\circ} 09^{\prime} 05^{\prime \prime} \mathrm{W}\end{array}$ & $\begin{array}{l}\text { Red } \\
\text { spruce }\end{array}$ & $\begin{array}{l}\text { Picea } \\
\text { rubens }\end{array}$ & 3 & $13.7(1.1)$ \\
\hline NEIGE-FM & $\begin{array}{l}47^{\circ} 19^{\prime} 20^{\prime \prime} \mathrm{N} \\
71^{\circ} 09^{\prime} 05^{\prime \prime} \mathrm{W}\end{array}$ & $\begin{array}{l}\text { Balsam } \\
\text { fir }\end{array}$ & $\begin{array}{l}\text { Abies } \\
\text { balsamea }\end{array}$ & 2 & $15.0(1.3)$ \\
\hline SIRENE & $\begin{array}{r}45^{\circ} 22^{\prime} 25^{\prime \prime} \mathrm{N} \\
71^{\circ} 55^{\prime} 22^{\prime \prime} \mathrm{W}\end{array}$ & $\begin{array}{l}\text { Red } \\
\text { pine }\end{array}$ & $\begin{array}{l}\text { Pinus } \\
\text { resinosa }\end{array}$ & 6 & $27.0(4.5)$ \\
\hline SIRENE & $\begin{array}{l}45^{\circ} 22^{\prime} 25^{\prime \prime} \mathrm{N} \\
71^{\circ} 55^{\prime} 22^{\prime \prime} \mathrm{W}\end{array}$ & Aspen & $\begin{array}{l}\text { Populus } \\
\text { tremuloides }\end{array}$ & 5 & $21.0(1.9)$ \\
\hline SIRENE & $\begin{array}{l}45^{\circ} 22^{\prime} 25^{\prime \prime} \mathrm{N} \\
71^{\circ} 55^{\prime} 22^{\prime \prime} \mathrm{W}\end{array}$ & $\begin{array}{l}\text { Black } \\
\text { cherry }\end{array}$ & $\begin{array}{l}\text { Prunus } \\
\text { serotina }\end{array}$ & 2 & $30.2(1.2)$ \\
\hline
\end{tabular}

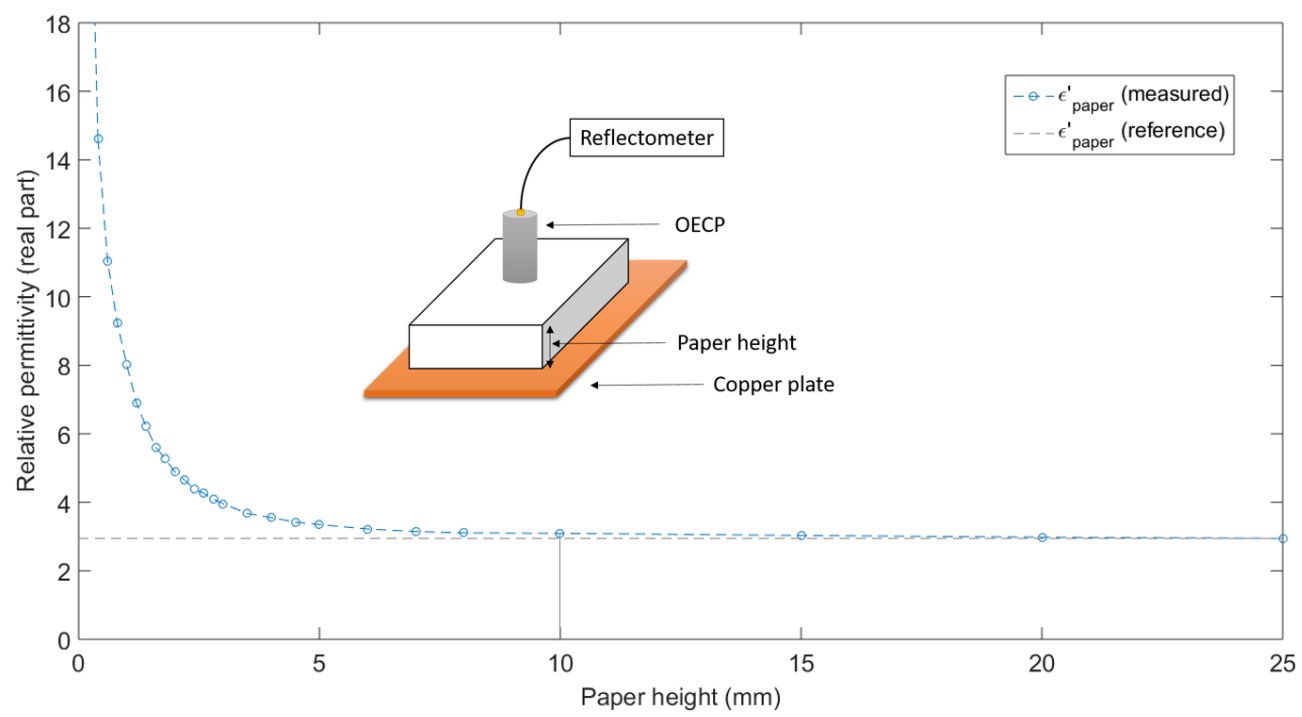

Figure 4. Real relative permittivity (unitless) at $\mathrm{L}$ band (1-2 GHz averaging) of a stack of paper sheets. The permittivity imaginary part is provided in the Supplement (Fig. S6).

result, measurements made on the same liquid standard vary less than $0.5 \%$ over 20 independent measurements.

To test contact with the flattened surface and evaluate OECP precision, solid sample measurements were also conducted (Fig. 6). The consensus between our measurements and the reference data deteriorates slightly to $3.3 \%$ for the real permittivity while using PTFE solid samples (Table 2). It should be noted that the $40 \%$ standard deviation in Table 1 for the imaginary part is mainly due to the fact that $\varepsilon^{\prime \prime}$ for PTFE is almost zero at L band; the fluctuations are still consistent with the real part. Overall, the lab tests on wellknown references confirmed that the OECP is suitable to acquire permittivity data with a precision of up to $3.3 \%$. With the solid samples, the reproducibility over 20 independent measurements fluctuates up to $1 \%$. 

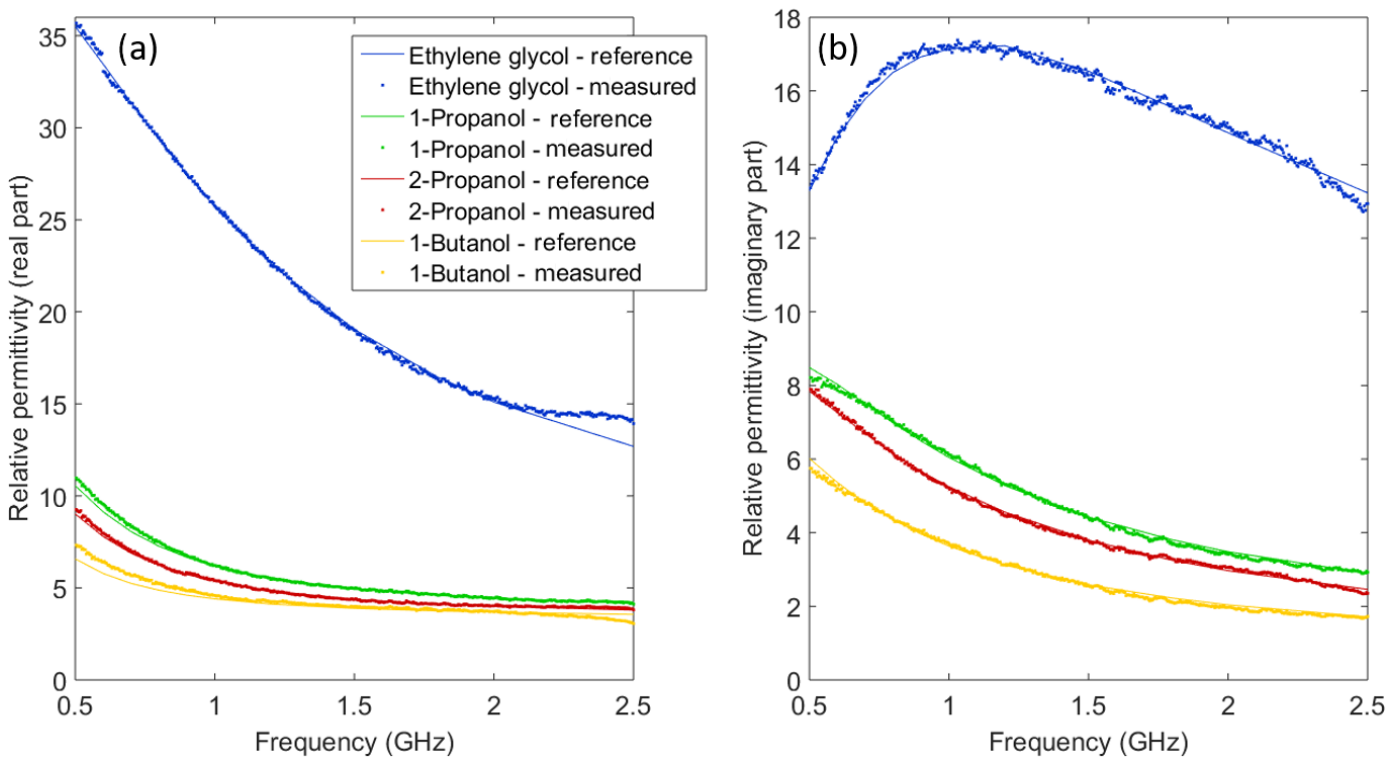

Figure 5. Real (a) and imaginary (b) relative permittivity (unitless) of various well-known liquid standards. The temperature of the reference curve is $20^{\circ} \mathrm{C}$.

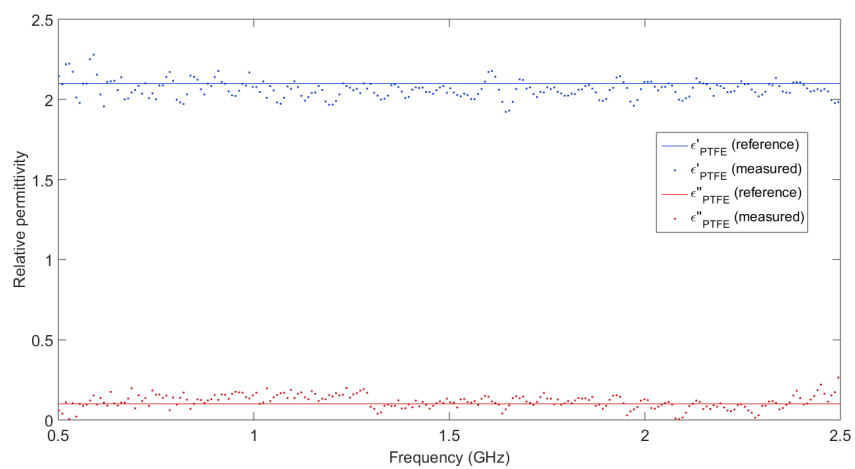

Figure 6. Real $\left(\varepsilon_{\mathrm{PTFE}}^{\prime}\right)$ and imaginary $\left(\varepsilon_{\mathrm{PTFE}}^{\prime \prime}\right)$ relative permittivity (unitless) of a block of polytetrafluoroethylene (PTFE).

\subsection{Dielectric characterization of tree trunks}

\subsubsection{Freeze-thaw state and species-specific permittivities}

Two patterns can be observed in Fig. 7: (1) the influence of sapwood depth on the radial profile and (2) the effect of the freeze-thaw state on the permittivity of the tree trunks. There are two distinct behaviors of the radial profiles during the thawed season. In the first several millimeters of the trunk, sapwood permittivity is higher due to a high water content, but permittivity decreases quickly to a lower and wellconstrained value in the heartwood (Fig. 7). It has to be noted that since the probed depth can reach up to $10 \mathrm{~mm}$, there is a bias toward lower permittivity near the interface sapwoodheartwood because the probe is measuring some dryer wood behind the actual sapwood.
Table 2. Root mean square error (RMSE) between the measured Lband relative permittivity value (real and imaginary parts) and the accepted value in the scientific literature for the data presented in Figs. 5 and 6. The percentage of error is in parentheses.

\begin{tabular}{lrr}
\hline Sample & RMSE $_{\text {real }}($ error \%) & RMSE $_{\text {ima }}($ error \%) \\
\hline Ethylene glycol & $0.16(0.8 \%)$ & $0.14(0.8 \%)$ \\
1-Propanol & $0.04(0.8 \%)$ & $0.08(1.7 \%)$ \\
2-Propanol & $0.042(0.9 \%)$ & $0.06(1.5 \%)$ \\
1-Butanol & $0.1(2.5 \%)$ & $0.068(2.5 \%)$ \\
PTFE & $0.068(3.3 \%)$ & $0.041(41.1 \%)$ \\
\hline
\end{tabular}

During winter, sap flow approaches zero, resulting in consistently low tree trunk permittivity across the whole range of trunk depths (Fig. 7). With the warmer days of spring, plant biological activity including sap flow recommences, resulting in an increase in sapwood thickness and peak permittivity. A midwinter thaw event occurred at OBS from 15 to 21 February. During those warmer days, the air temperature reached $5^{\circ} \mathrm{C}$. This event was sufficient to melt water inside the trees as the sapwood permittivity measurements of that day were similar to measurements taken during warmer spring temperatures when trees were biologically active. Since the ground was still frozen, it is unlikely that the trees started to photosynthesize. Another winter 1-day thaw event was captured at the Montmorency site on 8 March and displayed the same behavior as the OBS winter thaw event (data available in the Supplement, Fig. S5). These short thaw events caused a permittivity increase in the sapwood, which leads us to conclude that the vegetation freeze-thaw signal is particularly sensitive to short winter thaw events. 

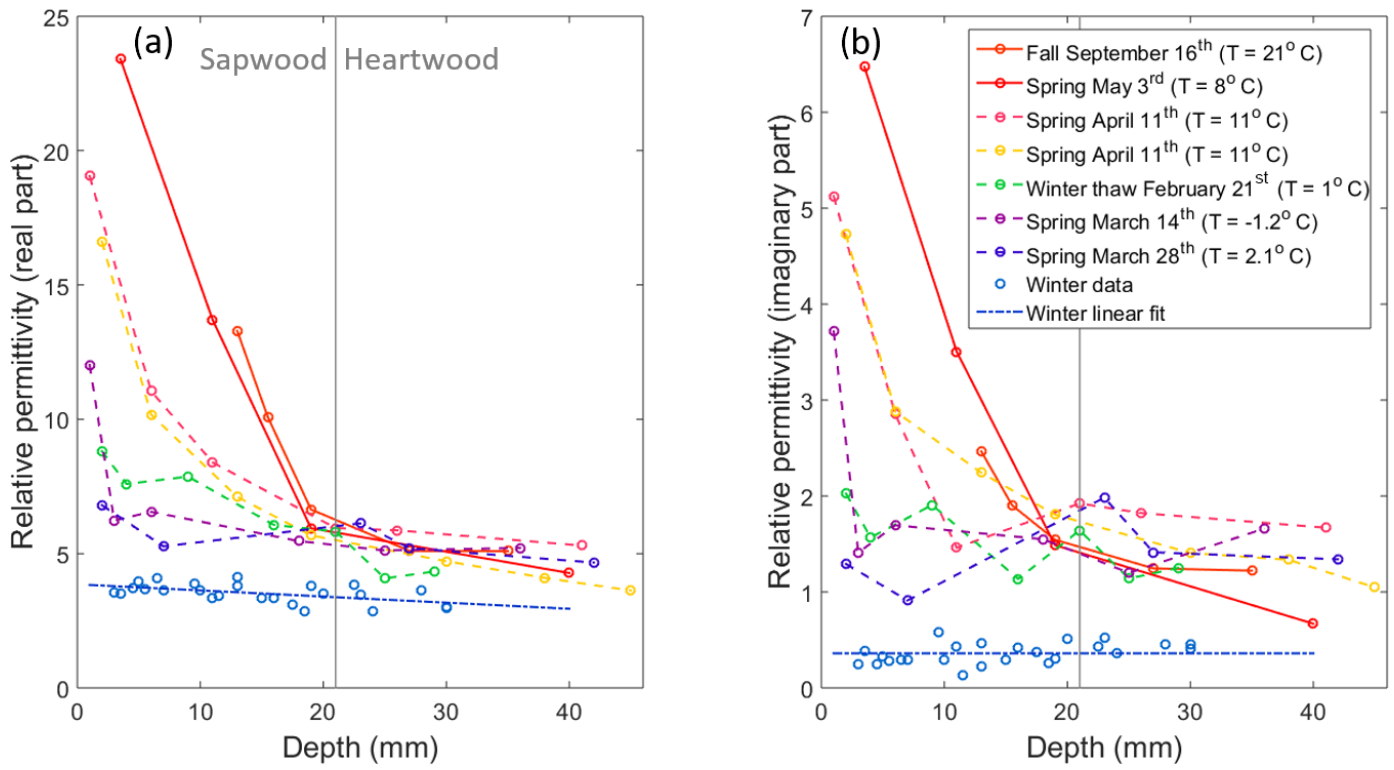

Figure 7. Trunk radial profile of the real (a) and imaginary (b) relative permittivity (unitless) at L band of black spruce at the OBS site in Saskatchewan. The gray vertical line approximates the sapwood depth estimated visually with tree core samples. The winter data were always collected well below the freezing point through the middle of winter.

Substantial differences were observed in the frozen permittivity of different tree species (Table 3 ), ranging from 3.52 to 9.13 for the real part and from 0.36 to 3.23 for the imaginary part. Evaluating thawed tree permittivity is challenging since permittivity changes with depth. However, it should be noted that L-band interaction would be higher with the sapwood because it is the outer layer of the tree and its permittivity is higher than the heartwood. To ensure a representative averaging of the sapwood permittivity, we did not make measurements too close to the interface between sapwood and heartwood to avoid a bias toward lower permittivity. Knowing that the sapwood thickness of the trees used in this study is around $2 \mathrm{~cm}$, the average permittivity reported in Table 3 for different thawed species was estimated by averaging the permittivity through the first centimeter under the bark using a trapezoidal numerical integration over that first centimeter. Again, significant differences were observed in the thawed permittivity of the tree species, ranging from 11.14 to 27.66 for the real part and from 3.05 to 9.33 for the imaginary part. Most of the thawed data date back to the end of spring (i.e., a fully thawed environment) and it should be kept in mind that some of these value patterns are to be expected during the growing season due to water storage in the trees and diurnal fluctuations as a result of tree hydrodynamics, as discussed below. Since all measurements used to calculate the permittivity of the thawed trees were collected in the latter part of the afternoon (between 15:00 and 18:00 local time), the evaluated permittivity corresponds to the daily minimum (see Sect. 4.3.2).

\subsubsection{Diurnal cycles of tree permittivity}

The continuous measurements on the red pine show that the OCEP captures diurnal permittivity cycles (Fig. 8a). Since permittivity is strongly correlated with liquid water content (i.e., tree water storage), the diurnal cycles are mainly linked to the tree's daily use of its water resources (Matheny et al., 2015). Water storage depletes during the day as a result of tree transpiration. During the late afternoon to early morning hours, trees replenish their water storage as a result of lower atmospheric demand and transpiration rates (e.g., Pappas et al., 2018). This is why maximum peak permittivity occurred during the night (between 18:00 and 20:00 local time) and the minima occurred between 15:00 and 17:00 local time. The soil moisture peaks measured by the EC-TM sensors in Fig. 8b correspond to rain events, with the major one occurring on the evening of 27 September. The days after rain events correspond to higher permittivity. After those rain events, there was a substantial amount of water available in the soil, enhancing water content in the sapwood.

\section{Discussion}

This study presents a new instrument for measuring tree trunk permittivity and demonstrates its applicability, precision and reliability for several common temperate and boreal tree species in North America. The OECP system is affordable (total costs are around USD 7000) when compared with other systems used to measure permittivity at microwave frequencies. The Canadian boreal forest is largely dominated by 
Table 3. Complex L-band relative permittivity for different tree species in thawed and frozen states. The standard deviation of the data is in parentheses when the number of trees probed was relevant for this statistic. $\varepsilon_{1 \mathrm{~cm} \text { average }}$ represents the average value of the trunk permittivity through the first centimeter under the bark, while $\varepsilon_{\text {average }}$ represents the average value across the whole radial profile as seen in Fig. 7. All data were taken between 15:00 and 18:00 local time. Detailed data are available in the Supplement for thawed trees (Figs. S1 to S5) and frozen trees (Fig. S7).

\begin{tabular}{llrrrr}
\hline Tree species & Site & \multicolumn{2}{c}{ Thawed } & \multicolumn{2}{c}{ Frozen } \\
\cline { 3 - 6 } & & $\varepsilon_{1 \mathrm{~cm} \text { average }}^{\prime}$ & $\varepsilon_{1 \mathrm{~cm} \text { average }}^{\prime \prime}$ & $\varepsilon_{\text {average }}^{\prime}$ & $\varepsilon_{\text {average }}^{\prime \prime}$ \\
\hline Black spruce & OBS & 19.20 & 5.19 & $3.52(0.36)$ & $0.36(0.11)$ \\
Larch & OBS & 13.63 & 3.39 & $4.02(0.58)$ & $1.49(0.20)$ \\
Red spruce & NEIGE-FM & 27.66 & 7.72 & $6.57(0.78)$ & $0.78(0.35)$ \\
Balsam fir & NEIGE-FM & 11.14 & 3.05 & - & - \\
Red pine & SIRENE & 19.38 & 6.26 & $8.80(0.31)$ & $3.17(0.14)$ \\
Aspen & SIRENE & $21.55(1.33)$ & $5.49(0.50)$ & $6.22(1.12)$ & $2.21(0.69)$ \\
Black cherry & SIRENE & 27.20 & 9.33 & $9.13(1.31)$ & $3.23(0.63)$ \\
\hline
\end{tabular}
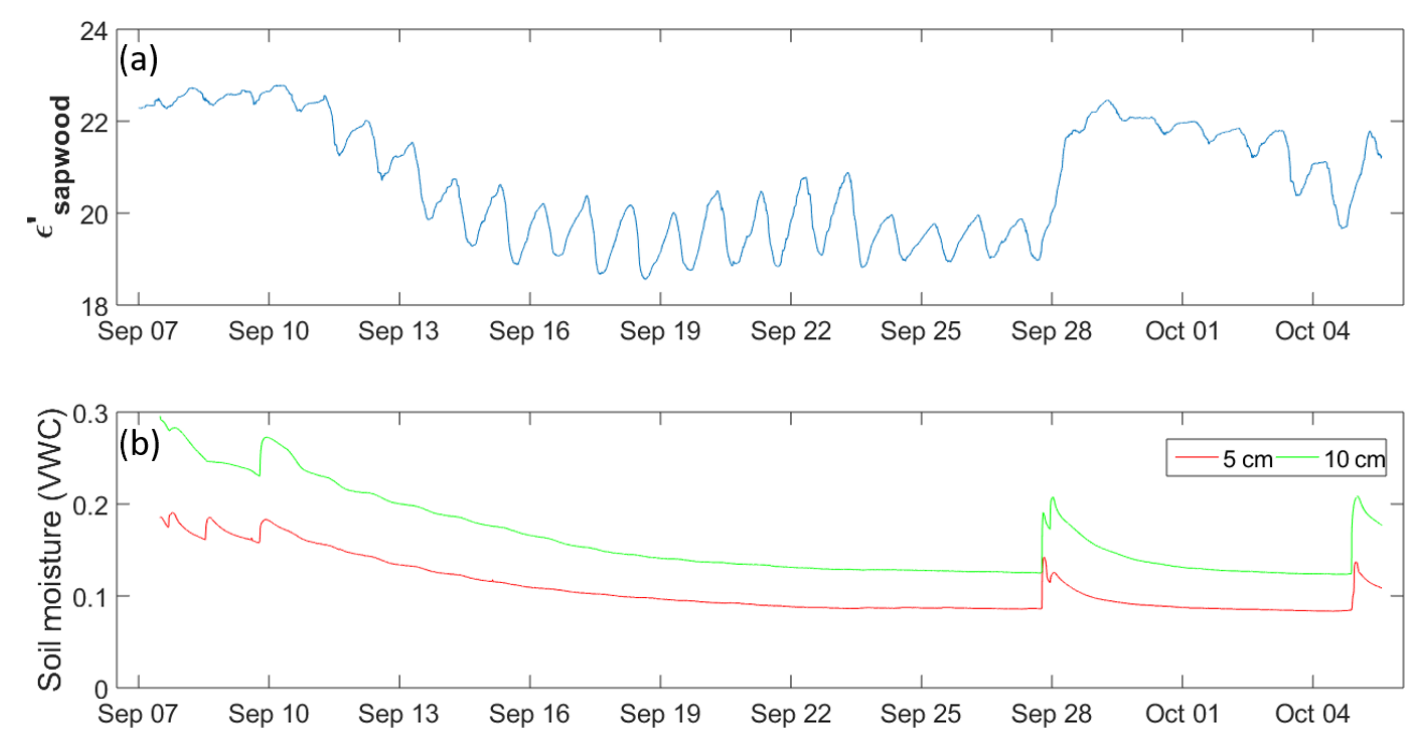

Figure 8. (a) Daily cycle of red pine sapwood L-band permittivity (unitless) at the SIRENE site, and (b) soil moisture at 5 and $10 \mathrm{~cm}$ of depth (EC-TM probe).

coniferous species, such as black spruce, which are evergreen trees with a small number of relatively thin branches. The influence of needles and branches on radiometric measurements is considered negligible at $\mathrm{L}$ band due to their size and quantity (Ferrazzoli et al., 2002). The diameter of branches needs to be a significant fraction of the wavelength to influence the signal. At $\mathrm{L}$ band, the wavelength (about $20 \mathrm{~cm}$ ) is much smaller than the diameter of branches for typical trees (black spruce) in boreal forests. Nevertheless, for deciduous forest, branch permittivity can still be measured using the same technique used for the trunk, but only for branches with a diameter greater than the OECP diameter. Measurements of broad-leaved leaf permittivity could be obtained by stacking a pile of leaves thicker than the probed depth (El-Rayes and Ulaby, 1987).
The period over which the data were collected allows for a better understanding of seasonal fluctuations in tree permittivity and its dependence on thaw events. The clear discrepancy between the freeze and thawed trunk permittivity is due to the water phase change and the limited biological activity of trees during winter. Tree species have a broad range of strategies for regulating their internal water storage and the resulting transpiration rates. Trees growing in an environment with annual freeze-thaw cycles have to be resistant to freezing-induced cavitation in their conductive xylem (plant tissues where water transport occurs). Even with anti-freeze mechanisms that allow them to keep $25 \%$ of their water in liquid state while air temperatures are below $-20^{\circ} \mathrm{C}$, trees still experience ice formations, at least in the outer layers of the tree trunk (Sparks et al., 2001). For example, coniferous species are characterized by smaller conduit diameters 
in their xylem to avoid internal damage (Sakai and Larcher, 1987). Sparks (2001) showed that there is no clear correlation between wood temperature and the volumetric water content inside the trunk. This absence of a correlation demonstrates the importance of obtaining direct permittivity measurements of vegetation material for radiometric modeling purposes because there is no reliable relationship between a tree's permittivity and its other easily measured physical properties. However, even if it was shown that the permittivity was quite stable when a tree was frozen, there are still some variations when air temperature was around $0{ }^{\circ} \mathrm{C}$. Hence, it would be interesting in future work to analyze with continuous measurements how the permittivity varies during freeze-thaw transitions.

Tree permittivity measurements can be of particular interest for the calibration and validation of microwave radiative transfer models for vegetation canopies. Radiative transfer models use the permittivity of the different layers (i.e., soil, snow and vegetation) to simulate wave-matter interactions. Since permittivity is challenging to measure in the field, it is typically derived from empirical relationships using more easily measurable parameters such as VWC and temperature. In Ferrazzoli et al. (2002), the dielectric constant of vegetation was computed with the semi-empirical formula given by Ulaby et al. (1986). The problem is that few of those relationships exist for vegetation and their applicability is limited. When the information for such parameterization is not available, models like $\omega-\tau$ compute the missing information through semi-empirical optimization. In situ permittivity measurements make it possible to validate and calibrate those empirical relationships using physicalbased microwave radiative transfer models. Tree permittivity is one of the main inputs in physical-based microwave radiative transfer models and can thus be considered as one of the main sources of uncertainty in the vegetation microwave emission and scattering properties calculation (Ferrazzoli et al., 2002; Kurum et al., 2011; Huang et al., 2017). In conjunction with L-band passive microwave ground-based radiometer and/or airborne observations in forested areas, tree permittivity measurements may inform microwave radiative transfer models to better understand and quantify the emission and scattering properties of vegetation. For example, Kurum et al. (2011) used an OECP with a vector network analyzer to measure tree permittivity in order to parameterize their first-order radiative transfer model for microwave radiometry of a forest canopy at $\mathrm{L}$ band. Furthermore, the permittivity measurements could be used to calibrate semiempirical vegetation microwave emission models such as the $\omega-\tau$ model, as the $\omega-\tau$ parameters should be linked to tree permittivity. Hence the OECP measurements, in conjunction with radiometer observations, could lead to $\omega-\tau$ calibration and link $\omega-\tau$ to tree hydraulic properties. Improving microwave radiative transfer model capabilities will thus enhance our capacity to decouple the signal coming from soil and vegetation and enhance soil moisture, freeze-thaw and tree hydraulics retrieval algorithms in boreal forest.

This study showed that tree permittivity is closely linked to tree hydraulic characteristics: during the thawed period, variations in tree permittivity are related to the tree's water storage, while in winter, tree freezing led to a strong decrease in permittivity. Hence, following empirical calibration (e.g., Matheny et al., 2015), the probe could be used to monitor the hydraulic properties of trees including water storage and the amount of frozen water in the tree. Compared to other methods to measure tree water storage, such as inserting soil moisture probes (Matheny et al., 2015), using several OECPs on a tree would make it possible to measure water storage and the amount of frozen water at different depths in the tree. However, for such long-term measurement applications, the biological reaction of the tree to the wound created by the cut made to insert the probe will have to be evaluated. Figure 8a shows a coherent signal over more than a month of measurements, suggesting that the tree's response to wounding is minimal; however, measurements over a longer period of time would be necessary to ensure the possibility of using the probe over full seasonal cycles to monitor the hydraulic functioning of trees. It is difficult to modify the dimensions of the probe without impacting its frequency limit since this is geometry dependent. Nevertheless, it is possible to reduce the dimensions of the probe for less invasive measurements, which will further increase the frequency limit. Moreover, it is possible to produce a series of probes operating up to higher frequency limits by reducing the size of their aperture, given that the limitation of the probed depth is acceptable.

\section{Conclusions}

This paper showed that the open-ended coaxial probe (OECP) is a suitable device to monitor the L-band permittivity (real and imaginary parts) of tree trunks. The OECP device that was developed displayed uncertainties under $3.3 \%$ with a solid reference target and under $2.5 \%$ with liquid standards. The permittivity of seven tree species was evaluated in both frozen and thawed states and revealed significant differences in the permittivity of those species. A clear distinction can be made between the dielectric characterization of (1) sapwood, for which the permittivity is high because of the high permittivity of water but decreases with depth, and (2) heartwood, for which the permittivity is low and constant. Our results indicate that the vegetation freeze-thaw state is sensitive to short winter thaw events. The OECP also proved to be precise enough to capture the growing season's diurnal cycle of fluctuations of tree water storage; however, its suitability for long-term continuous measurements requires further testing in order to quantify the impact of wounding effects. 
Future work will examine the suitability of the OECP for soil permittivity measurements. Having a single instrument able to measure the L-band permittivity of both soil and vegetation in situ would be a useful tool for calibrating and validating microwave radiative transfer models.

Data availability. The research data can be accessed by direct request to the author.

Supplement. The supplement related to this article is available online at: https://doi.org/10.5194/gi-7-195-2018-supplement.

Author contributions. AM, AR and Alain Royer designed the study. BF and FB designed the probe. AM, AR and CP collected the data. AM processed the data. All authors contributed to editing the paper.

Competing interests. The authors declare that they have no conflict of interest.

Acknowledgements. This work was made possible thanks to the contributions of the Canadian Space Agency (CSA), Natural Sciences and Engineering Research Council of Canada (NSERC) and Canada Foundation for Innovation (CFI). Christoforos Pappas acknowledges the support of the Swiss National Science Foundation (SNSF), the Stavros Niarchos Foundation and the ETH Zurich Foundation (grants P2EZP2_162293 and P300P2_174477). We thank Bertrand Reulet for providing us with equipment for early tests, Atelier Pedro for manufacturing the probe, Warren Helgason for his logistical help, Bruce Johnson, Peter Toose, Joël Lemay and Mariam El-Amine for their help in the field, and Patrick Cliche and Gabriel Diab for their help with technical issues. We would also like to thank the three reviewers for helping us to improve the paper.

Edited by: Mehrez Zribi

Reviewed by: S. Bircher and one anonymous referee

\section{References}

Artemov, V. and Volkov, A.: Water and Ice Dielectric Spectra Scaling at $0^{\circ} \mathrm{C}$, Ferroelectrics, 466, 158-165, 2014.

Bergeron, O., Margolis, H., Black, A., Coursolle, C., Bunn, A., Barr, A., and Wofsy, S.: Comparison of carbon dioxide fluxes over three boreal black spruce forests in Canada, Glob. Change. Biol., 13, 89-107, 2007.

Bircher, S., Demontoux, F., Razafindratsima, S., Zakharova, E., Drusch, M., Wigneron, J.-P., and Kerr, Y.: L-Band Relative Permittivity of Organic Soil Surface Layers - A New Dataset of Resonant Cavity Measurements and Model Evaluation, Remote Sens.-Basel, 8, 1024, 2016.
Blackham, D. and Pollard, R.: An improved technique for permittivity measurements using a coaxial probe, IEEE T. Instrum. Meas., 46, 1093-1099, 1997.

Brandt, J. P., Flannigan, M. D., Maynard, D. G., Thompson, I. D., and Volnet, W. J. A.: An introduction to Canada's boreal zone: ecosystem processes, health, sustainability, and environmental issues, Environ. Rev., 21, 207-226, 2013.

Chapin, F., Sturm, M., Serreze, M., McFadden, J., Key, J., Lloyd, A., McGuire, A., Rupp, T., Lynch, A., Schimel, J., Beringer, J., Chapman, W., Epstein, H., Euskirchen, E., Hinzman, L., Jia, G., Ping, C., Tape, K., Thompson, C., Walker, D., and Welker, J.: Role of land-surface changes in Arctic summer warming, Science, 310, 657-660, 2005.

Cole, K. and Cole, R.: Dispersion and absorption in dielectrics Alternating current characteristics, J. Chem. Phys., 9, 341-351, 1941.

Demontoux, F., Le Crom, B., Ruffie, G., Wigneron, J.-P., Grant, J., Mironov, V., and Lawrence, H.: Electromagnetic characterization of soil-litter media: Application to the simulation of the microwave emissivity of the ground surface in forests, The European Physical Journal Applied Physics, 44, 303-315, 2008.

Demontoux, F., Razafindratsima, S., Bircher, S., Ruffie, G., Bonnaudin, F., Jonard, F., Wigneron, J.-P., Sbartaï, Z. M., and Kerr, Y.: Efficiency of end effect probes for in situ permittivity measurements in the $0.5-6 \mathrm{GHz}$ frequency range and their application for organic soil horizons study, Sensor. Actuat. A-Phys., 254, 78-88, 2016.

Derksen, C. , Xu, X., Scott Dunbar, R., Colliander, A., Kim, Y., Kimball, J. S., Black, T. A., Euskirchen, E., Langlois, A., Loranty, M. M., Marsh, P., Rautiainen, K., Roy, A., Royer, A., and Stephens, J.: Retrieving landscape freeze/thaw state from Soil Moisture Active Passive (SMAP) radar and radiometer measurements, Remote Sens. Environ., 194, 48-62, 2017.

El-Rayes, M. and Ulaby, F.: Microwave dielectric spectrum of vegetation - Part I: Experimental observations, IEEE T. Geosci. Remote, GE-25, 541-549, 1987.

Entekhabi, D., Njoku, E., O’Neill, P., Kellogg, K., Crow, W., Edelstein, W., Entin, J., Goodman, S., Jackson, T., Jackson, J., Kimball, J., Piepmeier, J., Koster, R., Martin, N., McDonald, K., Moghaddam, M., Moran, S., Reichle, R., Shi, J., Spencer, M., Thurman, S., Tsang, L., and Van Zyl, J.: The Soil Moisture Active Passive (SMAP) mission, P. IEEE, 98, 704-716, 2010.

Entekhabi, D., Yueh, S., O’Neill, P.E., Wood, E. F., Njoku, E. G., Entin, J. K., and Kellogg, K. H.: The NASA Soil Moisture Active Passive (SMAP) Mission Status and Early Results, Proc. EGU General Assembly Conference Abstracts, 17, 5973, 2015.

Ferrazzoli, P., Guerriero, L., and Wigneron, J.-P.: Simulating LBand Emission of Forests in View of Future Satellite Applications, IEEE T. Geosci. Remote, 40, 2700-2708, 2002.

Filali, B., Rhazi, J.-E., and Ballivy, G.: Measurement of the dielectric properties of concrete by a large coaxial probe with open end, Can. J. Phys., 84, 365-379, 2006.

Filali, B., Boone, F., Rhazi, J.-E., and Ballivy, G.: Design and calibration of a large open-ended coaxial probe for the measurement of the dielectric properties of concrete, IEEE T. Microw. Theory, 56, 2322-2328, 2008.

Franchois, A., Pineiro, Y., and Lang, R.: Microwave permittivity measurements of two conifers, IEEE T. Geosci. Remote, 36, 1384-1395, 1998. 
Ghodgaonkar, D., Varadan, V. V., and Varadan V. E.: Free-Space Measurement of Complex Permittivity and Complex Permeability of Magnetic Materials at Microwave Frequencies, IEEE T. Instrum. Meas., 39, 387-394, 1990.

Gower, S., Vogel, J., Norman, J., Kucharik, C., Steele, S., and Stow, T.: Carbon distribution and aboveground net primary production in aspen, jack pine, and black spruce stands in Saskatchewan and Manitoba, Canada, J. Geophys. Res., 102, 29029-29041, 1997.

Gregory, A. and Clarke, R.: Tables of the complex permittivity of dielectric reference liquids at frequencies up to $5 \mathrm{GHz}$, National Physical Laboratory technical report, MAT 23, Teddington, Middlesex, UK, 87 pp., 2012.

Hakki, B. and Coleman, P.: A dielectric resonator method of measuring inductive capacities in the millimeter range, IEEE T. Microw. Theory, 8, 402-410, 1960.

Huang, H., Tsang, L., Njoku, E., Colliander, A., Liao, T.-H., and Ding, K.-H.: Propagation and scattering by a layer of randomly distributed dielectric cylinders using Monte Carlo simulations of 3-D Maxwell equations with applications in microwave interactions with vegetation, IEEE Access, 5, 11985-12003, 2017.

Jackson, T. and Schmugge, T.: Vegetation effects on the microwave emission of soils, Remote Sens. Environ., 36, 203-212, 1991.

Kerr, Y. H., Waldteufel, P., Wigneron, J. P., Delwart, S., Cabot, F. O., Boutin, J., Escorihuela, M. J., Font, J., Reul, N., Gruhier, C., and Juglea, S. E.: The SMOS mission: New tool for monitoring key elements of the global water cycle, IEEE T. Geosci. Remote, 98, 666-687, 2010.

Kerr, Y., Waldteufel, P., Richaume, P., Wigneron, J., Ferrazzoli, P., Mahmoodi, A., Al Bitar, A., Cabot, F., Gruhier, C., Juglea, S., Leroux, D., Mialon, A., and Delwart, S.: The SMOS soil moisture retrieval algorithm, IEEE T. Geosci. Remote, 50, 13841403, 2012.

Kim, Y., Kimball, K., Zhang, K., Didan, K., Velicogna, I., and McDonald, K.: Attribution of divergent northern vegetation growth responses to lengthening non-frozen seasons using satellite optical-NIR and microwave remote sensing, Int. J. Remote Sens., 35, 3700-3721, 2014.

Klingshirn, C. F.: Semiconductor Optics - Graduate Texts in Physics (Chapter: Kramers-Kronig Relations), Springer, Berlin, Heidelberg, 849 pp., 2012.

Konings, A. and Gentine, P.: Global variations in ecosystem-scale isohydricity, Glob. Change. Biol., 23, 891-905, 2017.

Konings, A., Williams, A., and Gentine, P.: Sensitivity of grassland productivity to aridity controlled by stomatal and xylem regulation, Nat. Geosci., 10, 284-290, 2017a.

Konings, A., Yu, Y., Xu, L., Yang, Y., Schimel, D., and Saatchi, S.: Active microwave observations of diurnal and seasonal variations of canopy water content across the humid African tropical forests, Geophys. Res. Lett., 44, 2290-2299, 2017 b.

Kurum, P., Lang, R., O’Neil, P., Joseph, A., Jackson, T., and Cosh, M., A First-Order Radiative Transfer Model for Microwave Radiometry of Forest Canopies at L-Band, IEEE T. Geosci. Remote, 49, 3167-3179, 2011.

Kurum, P., O’Neil, P., Lang, R., Joseph, A., Cosh, M., and Jackson, T.: Effective tree scattering and opacity at L-band, Remote Sens. Environ., 118, 1-9, 2012.

Le Vine, D. M., Lagerloef, G. S., and Torrusio, S.: Aquarius and remote sensing of sea surface salinity from space, P. IEEE, 98, 688-703, 2010.
Maeglin, R.: Increment cores: how to collect, handle and use them, General technical report FPL-25 for the U.S. Department of Agriculture, Forest Service, Forest Products Laboratory, Madison, Wisconsin, United States, 18 pp., 1959.

Matheny, A., Bohrer, G., Garrity, S., Morin, T., Howard, C., and Vogel, C.: Observations of stem water storage in trees of opposing Hydraulic strategies, Ecosphere, 9, 6, 165, 2015.

Mätzler, C.: Applications of the interaction of microwaves with the natural snow cover, Remote Sensing Review, 2, 259-387, 1987.

McDonald, K., Zimmermann, R., and Kimball, J.: Diurnal and spatial variation of xylem dielectric constant in Norway spruce (picea abies [L.] Karst.) as related to microclimate, xylem sap flow, and xylem chemistry, IEEE T. Geosci. Remote, 40, 2063 2082, 2002.

McDonald, K., Kimball, J., Njoku, E., Zimmerman, R., and Zhao, M.: Variability in springtime thaw in the terrestrial high latitudes: monitoring a major control on the biospheric assimilation of atmospheric $\mathrm{CO}_{2}$ with spaceborne microwave remote sensing, Earth Interact., 8, 20, 23 pp., 2004.

Mo, T., Choudhury, B., Schmugge, T., Wang, J., and Jackson, T.: A model for microwave emission from vegetation-covered fields, J. Geophys. Res., 87, 11229-11237, 1982.

Nyshadham, A., Sibbald, C., and Stuchly, S.: Permittivity measurements using open-ended sensors and reference liquid calibration - An uncertainty analysis, IEEE T. Microw. Theory, 40, 305-314, 1991.

Panneer Selvam, B., Laudon, H., Guillemette, F., and Berggren, M.: Influence of soil frost on the character and degradability of dissolved organic carbon in boreal forest soils, J. Geophys. Res.Biogeo., 121, 829-840, 2016.

Pappas, C., Matheny, A., Baltzer, J., Barr, A., Black, T., Bohrer, G., Detto, M., Maillet, J., Roy, A., Sonnentag, O., and Stephens, J.: Boreal tree hydrodynamics: asynchronous, diverging, yet complementary, Tree Physiol., 38, 953-964, https://doi.org/10.1093/treephys/tpy043, 2018.

Quiñonez-Piñón, R. and Valeo, C.: Allometry of Sapwood Depth in Five Boreal Trees, Forests, 11, 8, 457, 2017.

Rautiainen, K., Lemmetyinen, J., Pulliainen, J., Vehviläinen, J., Drusch, M., Kontu, A., Kainulainen, J., and Seppanen, J.: Lband radiometer observations of soil processes at boreal and subArctic environments, IEEE T. Geosci. Remote, 50, 1483-1497, 2012.

Rautiainen, K., Lemmetyinen, J., Schwank, M., Kontu, A., Ménard, C. B., Mätzler, C., Drusch, M., Wiesmann, A., Ikonen, J., and Pulliainen, J.: Detection of soil freezing from L-band passive microwave observations, Remote Sens. Environ., 147, 206-218, 2014.

Rautiainen, K., Parkkinen, T., Lemmetyinen, J., Schwank, M., Wiesmann, A., Ikonen, J., Derksen, C., Davydov, S., Davydova, A., Boike, J., and Langer, M.: SMOS prototype algorithm for detecting autumn soil freezing, Remote Sens. Environ., 180, 346360, 2016.

Roy, A., Royer, A., Wigneron, J.-P., Langlois, A., Bergeron, J., and Cliche, P.: A simple parameterization for a boreal forest radiative transfer model at microwave frequencies, Remote Sens. Environ., 124, 371-383, 2012.

Roy, A., Royer, A., and Hall, R.: Relationship between forest microwave transmissivity and structural parameters for the Cana- 
dian boreal forest, IEEE Geosci. Remote S., 11, 1802-1806, 2014.

Roy, A., Royer, A., Derksen, C., Brucker, L., Langlois, A., Mialon, A., and Kerr, Y. H.: Evaluation of Spaceborne L-Band Radiometer Measurements for Terrestrial Freeze/Thaw Retrievals in Canada, IEEE J. Sel. Top. Appl., 8, 4442-4459, 2015.

Roy, A., Royer, A., St-Jean-Rondeau, O., Montpetit, B., Picard, G., Mavrovic, A., Marchand, N., and Langlois, A.: Microwave snow emission modeling uncertainties in boreal and subarctic environments, The Cryosphere, 10, 623-638, https://doi.org/10.5194/tc10-623-2016, 2016.

Roy, A., Toose, P., Williamson, M, Rowlandson, T., Derksen, C., Royer, A., Lemmetyinen, J., Berg, A., and Arnold, L.: Response of L-Band brightness temperatures to freeze/thaw and snow dynamics in a prairie environment from ground-based radiometer measurements, Remote Sens. Environ., 191, 67-80, 2017.

Sakai, A. and Larcher, W.: Frost survival of plants. Springer-Verlag Berlin Heidelberg, New York, USA, 321 pp., 1987.

Schmugge, T., Jackson, T., and McKim, H.: Survey of Methods for Soil Moisture Determination, Water Resour. Res., 16, 961-979, 1980.

Sparks, J., Campbell, G., and Black, R.: Water content, hydraulic conductivity, and ice formation in winter stems of Pinus contorta: a TDR case study, Oecologia, 127, 468-475, 2001.

Stuchly, M., Athey, T., Samaras, G., and Taylor, G.: Measurement of radio frequency permittivity of biological tissues with an openended coaxial line: Part I and II, IEEE T. Microw. Theory, MMT30, 87-92, 1982.

Topp, G., Davis, G., and Annan, A.: Electromagnetic determination of soil water content: Measurements in coaxial transmission lines, Water Resour. Res., 16, 574-582, 1980.

Ulaby, F., Razani, M., and Dobson, M.: Effects of vegetation cover on the microwave radiometric sensitivity to soil moisture, IEEE T. Geosci. Remote, GE-21, 51-61, 1983.

Ulaby, F., Moore, R. K., and Fung, A. K.: Microwave Remote Sensing: Active and Passive, Vol. III, From Theory to Applications, Artech House, Dedham, MA, USA, 1986.

Ulaby, F. and Long, D.: Microwave Radar and Radiometric Remote Sensing, The University of Michigan Press, Ann Arbor, Michigan, USA, 1116 pp., 2014.
Way, J., Paris, J., Kasischke, E., Slaughter, C., Viereck, L., Christensen, N., Dobson, M., Ulaby, F., Richards, J., Milne, A., Sieber, A., Ahern, F., Simonett, D., Hoffer, R., Imhoff, M., and Weber, J.: The effect of changing environmental conditions on microwave signatures of forest ecosystems : preliminary results of the March 1988 Alaskan aircraft SAR experiment, Int. J. Remote Sens., 11, 1119-1144, 1990.

Wang, W.-C., Pinto, J., and Yung, Y.: Climatic effects due to halogenated compounds in the Earth's atmosphere, J. Atmos. Sci., 37, 333-338, 1980.

Webster, J.: Electrical Measurement, Signal Processing, and Displays, CRC Press, Boca Raton, USA, 768 pp., 2003.

Wigneron, J.-P., Pardé, M., Waldteufel, P., Chanzy, A., Kerr, Y., Schmidl, S., and Skou, N.: Characterizing the dependence of vegetation model parameters on crop structure, view angle and polarization at L-band, IEEE T. Geosci. Remote, 42, 416-425, 2004.

Wigneron, J.-P., Kerr, Y.,Waldteufel, P., Saleh, K., Escorihuela, M.J., Richaume, P., Ferrazzoli, P., Derosnay, P., Gurney, R., Calvet, J.-C., Grant, J., Guglielmetti, M., Hombuckle, B., Mätler, C., Pellarin, T., and Schwank, M.: L-band Microwave Emission of the Biosphere (L-MEB) Model : Description and calibration against experimental data sets over crop fields, Remote Sens. Environ., 107, 639-655, 2007.

Wigneron, J.-P., Jackson, T. J., O’Neill, P., Lannoy, De, de Rosnay, P., Walker, J. P., Ferrazzoli, P., Mironov, V., Bircher, S., Grant, J. P., Kurum, M., Schwank, M., Munoz-Sabater, J., Das, N., Royer, A., Al-Yaari, A., Al Bitar, A., Fernandez-Moran, R., Lawrence, H., Mialon, A., Parrens, M., Richaume, P., Delwart, S., and Kerr, Y.: Modelling the passive microwave signature from land surfaces: a review of recent results and application to the L-band SMOS and SMAP soil moisture retrieval algorithms, Remote Sens. Environ., 192, 238-262, 2017.

Zhang, K., Kimball, J., Kim, Y., and McDonald, K.: Changing freeze-thaw seasons in northern high latitudes and associated influences on evapotranspiration, Hydrol. Process., 25, 4142-4151, 2011. 